\title{
High Rate of Epidermal Growth Factor Receptor- Mutated Primary Lung Cancer in Patients with Primary Breast Cancer
}

\section{Tianyu Zeng}

the First Affiliated Hospital of Nanjing Medical University

Hai Xu

the First Affiliated Hospital of Nanjing Medical University

Yincheng Liu

the First Affiliated Hospital of Nanjing Medical University

Yiqi Yang

the First Affiliated Hospital of Nanjing Medical University

\section{Fan Yang}

the First Affiliated Hospital of Nanjing Medical University

Mengzhu Yang

the First Affiliated Hospital of Nanjing Medical University

Chunxiao Sun

the First Affiliated Hospital of Nanjing Medical University

Shengnan Bao

the First Affiliated Hospital of Nanjing Medical University

Yijia Hua

the First Affiliated Hospital of Nanjing Medical University

\section{Xueqi Yan}

the First Affiliated Hospital of Nanjing Medical University

\section{Yaozhou He}

the First Affiliated Hospital of Nanjing Medical University

\section{Xi Wang}

the First Affiliated Hospital of Nanjing Medical University

\section{Mengping Jiang}

the First Affiliated Hospital of Nanjing Medical University

Yan Liang

the First Affiliated Hospital of Nanjing Medical University

\section{Xiang Huang}

the First Affiliated Hospital of Nanjing Medical University

Jun Li 
the First Affiliated Hospital of Nanjing Medical University

\section{Ziyi Fu}

the First Affiliated Hospital of Nanjing Medical University

Wei Li

the First Affiliated Hospital of Nanjing Medical University

Yongmei Yin ( $\nabla$ ymyin@njmu.edu.cn )

the First Affiliated Hospital of Nanjing Medical University

\section{Research Article}

Keywords: Neoplasms, multiple primary, Breast neoplasms, Lung neoplasms, Epidermal Growth Factor Receptor

Posted Date: August 18th, 2021

DOl: https://doi.org/10.21203/rs.3.rs-763128/v1

License: @ (i) This work is licensed under a Creative Commons Attribution 4.0 International License. Read Full License 


\section{Abstract \\ Background}

With increased survival in breast cancer, resulting from advances in treatment, patients incur the possibility of subsequent primary malignancies, especially lung cancer. The aim of this study was to assess the frequency of CT-detected pulmonary ground-glass nodules and lung cancer following breast cancer diagnosis, the associations between breast cancer and lung cancer, the pathological features of double primary cancer, and the status of epidermal growth factor receptor (EGFR) mutations in second primary lung cancer.

\section{Methods}

Clinical data from more than 8000 individuals who were diagnosed with primary breast cancer at Jiangsu Province Hospital (Jiangsu, China) between January 2008 and December 2020 were retrospectively analyzed.

\section{Results}

Of the 8048 patients, $55(0.7 \%)$ were diagnosed with a second primary lung cancer, which accounted for approximately $14.8 \%$ of the pulmonary ground-glass opacity (GGO) detected. The incidence was higher than in the general female population (standardized incidence ratio 1.4 [95\% confidence interval $(\mathrm{Cl})$ : 1.25-1.55]). Patients who experienced a second primary lung cancer exhibited a significantly higher rate of EGFR mutation (78.5\%) than those with lung adenocarcinoma alone, with most exhibiting low-grade malignancy, older age, estrogen receptor negativity, low Ki67, and no lymph node metastasis.

\section{Conclusions}

Breast cancer patients, especially those with low-grade malignancy, were at high risk for developing primary lung cancer. For isolated GGO in patients with high-risk factors, clinicians should insist on close follow-up. Furthermore, EGFR may play an important role in primary lung adenocarcinomas and breast cancer.

\section{Introduction}

Breast cancer and lung cancer are the two most frequently diagnosed malignancies, have the highest morbidity, and are the leading causes of cancer-related deaths in women worldwide ${ }^{1}$. Advances in treatment and improved surgical techniques have extended the lifespan of breast cancer patients. However, with this prolonged survival, the risk of a second primary cancer has also increased. 
Approximately $10 \%$ of breast cancer patients experience another malignancy within 10 years after diagnosis, $5 \%$ of which are lung cancers ${ }^{2,3}$.

What also warrants attention is that the number of women with a double primary cancer may also be increased. The most frequently observed second primary cancers in breast cancer patients are hematological tumors, melanomas, and cancers of the digestive tract, female reproductive system, lung, thyroid, ovary, and urinary tract. ${ }^{4-6}$ Many studies have demonstrated that a second primary cancer is associated with a lower survival rate 7,8 . However, little is known about secondary lung cancers that follow breast cancer. Although several epidemiological studies have investigated lung cancer secondary to breast cancer $^{9-13}$, assessed high-risk factors ${ }^{14-17}$ for double primary malignancies, and examined the directional associations of estrogen receptor (ER) status ${ }^{14}$ in second lung cancers, the clinical characteristics of primary lung cancer following breast cancer have not been comprehensively described. Therefore, this study aimed to evaluate breast cancer patients with a second primary lung cancer to explore the clinicopathological characteristics of primary lung cancer after breast cancer and to analyze the related associations of breast cancer with primary lung cancer, especially the mutation of EGFR in lung cancer, which may provide new insights for more precise treatment of tumors.

\section{Results}

\section{The incidence of primary lung cancer in patients with primary breast cancer}

A total of 8048 patients with breast cancer were eligible for analysis. GGOs were detected in 403 (5.0\%), and a definitive diagnosis of lung cancer was made in $55(0.7 \%)$. Based on the incidence of cancer in China in $2015^{18}$, higher rates of second primary lung cancer occurred among breast cancer patients compared with the general female population (SIR 1.4 [95\% Cl 1.25-1.55]).

\section{Clinicopathological Characteristics Of Patients With Double Primary Cancers}

The clinicopathological characteristics of patients with breast cancer, including age, family history of malignancy, tumor size, histological type, lymph node metastasis, and clinical grade, are summarized in Table 1. Patients who experienced a second primary lung cancer were more likely to be older $(p=0.04)$. Patients with ER-negative breast cancer $(p=0.01)$, low Ki67 $(p=0.01)$, and no lymph node metastasis ( $p$ $=0.01$ ) were more likely to develop a second primary lung cancer. There were no statistically significant differences in the other characteristics. 
Table 1

Clinicopathological characteristics of breast cancer patients.

\begin{tabular}{|c|c|c|c|c|}
\hline Variable & BC-LC & BC alone & p-value & SIR \\
\hline \multicolumn{3}{|l|}{ Age, years } & \multirow[t]{3}{*}{0.0407} & \\
\hline$\leq 50$ & 22 & 204 & & 0.45 \\
\hline$>50$ & 33 & 144 & & 2.19 \\
\hline \multicolumn{5}{|c|}{ Family history of malignancy } \\
\hline Yes & 16 & 248 & \multirow[t]{3}{*}{0.2439} & 2.46 \\
\hline No & 38 & 94 & & 1.47 \\
\hline Unknown & 1 & 6 & & 0.08 \\
\hline \multicolumn{5}{|c|}{ Tumor size } \\
\hline$\leq 2 \mathrm{~cm}$ & 36 & 85 & \multirow[t]{2}{*}{0.2430} & 1.19 \\
\hline$>2 \mathrm{~cm}$ & 19 & 263 & & 2.77 \\
\hline \multicolumn{5}{|c|}{ Estrogen receptor } \\
\hline Positive & 42 & 171 & \multirow[t]{2}{*}{0.0101} & 1.03 \\
\hline Negative & 13 & 177 & & 2.11 \\
\hline \multicolumn{5}{|c|}{ Progesterone receptor } \\
\hline Positive & 29 & 157 & \multirow[t]{2}{*}{0.0133} & 1.08 \\
\hline Negative & 26 & 191 & & 1.04 \\
\hline \multicolumn{5}{|l|}{ HER2 } \\
\hline Positive & 19 & 105 & \multirow[t]{2}{*}{0.1697} & 1.32 \\
\hline Negative & 36 & 243 & & 0.93 \\
\hline \multicolumn{5}{|l|}{ Ki67 } \\
\hline$<30 \%$ & 33 & 114 & \multirow[t]{3}{*}{0.0109} & 1.79 \\
\hline$\geq 30 \%$ & 17 & 152 & & 1.02 \\
\hline Unknown & 5 & 82 & & 0.95 \\
\hline
\end{tabular}

Data are presented as $\mathrm{n}$ unless otherwise indicated.

BC, breast cancer; HER2, human epidermal growth factor receptor 2; LC, lung cancer; SIR, standardized incidence ratio 


\begin{tabular}{|lllll|}
\hline Variable & BC-LC & BC alone & p-value & SIR \\
\hline Yes & 11 & 169 & 0.0136 & 1.07 \\
\hline No & 44 & 179 & 2.19 \\
\hline Grade & 41 & 245 & 3.04 \\
\hline $1-2$ & 14 & 103 & 0.93 \\
\hline 3 & & & & \\
\hline History of smoking & 2 & 18 & \\
\hline Yes & 53 & 330 & \\
\hline No/Unknown & 31 & 186 & \\
\hline Radiotherapy & 24 & 162 & \\
\hline Yes & & & \\
\hline None/Unknown & & & \\
\hline Data are presented as n unless otherwise indicated. & \\
\hline $\begin{array}{l}\text { BC, breast cancer; HER2, human epidermal growth factor receptor 2; LC, lung cancer; SIR, standardized } \\
\text { incidence ratio }\end{array}$
\end{tabular}

Of the 55 patients, 54 (98.2\%) had lung adenocarcinoma and 1 (1.8\%) had small cell lung cancer. Among these patients, EGFR status was assessed in 28 , with an EGFR mutation rate of $78.5 \%(n=22)$. We analyzed the relationship between EGFR mutation and breast cancer subtype and found that ER-positive patients were more likely to have EGFR mutations (Table 2a, Fig. 1). The progesterone receptor, human epidermal growth factor 2 (HER2), and Ki67 status had no statistically significant correlation with EGFR status (Table 2b, c, d).

Table 2

a. Correlation of EGFR mutation and ER status of breast cancer

\begin{tabular}{|lllll|}
\hline No. & \multicolumn{2}{l}{ ER } & Total \\
\cline { 3 - 4 } & Negative & Positive & \\
\hline \multirow{2}{*}{ EGFR } & Wild-type & 3 & 3 & 6 \\
\cline { 2 - 4 } & Mutated & 0 & 22 & 22 \\
\hline Total & 3 & 25 & 28 \\
\hline Fisher's exact test, $p=0.006$ & & \\
\hline \multicolumn{2}{|l|}{ EGFR, epidermal growth factor receptor; ER, estrogen receptor } \\
\hline
\end{tabular}


Table 2

b. Correlation of EGFR mutation and PR status of breast cancer

\begin{tabular}{|lllll|}
\hline \multirow{2}{*}{ No. } & \multicolumn{2}{l}{ PR } & Total \\
\cline { 3 - 4 } & & Negative & Positive & \\
\hline EGFR & Wild-type & 4 & 2 & 6 \\
\cline { 2 - 5 } & Mutated & 7 & 15 & 22 \\
\hline Total & 11 & 17 & 28 \\
\hline Fisher's exact test, $\mathrm{p}=0.174$ & & \\
\hline EGFR, epidermal growth factor receptor; PR, progesterone receptor \\
\hline
\end{tabular}

Table 2

b. Correlation of EGFR mutation and PR status of breast cancer

\begin{tabular}{|lllll|}
\hline No. & \multicolumn{2}{l}{ PR } & Total \\
\cline { 3 - 4 } & Negative & Positive & \\
\hline EGFR & Wild-type & 4 & 2 & 6 \\
\cline { 2 - 5 } & Mutated & 7 & 15 & 22 \\
\hline Total & 11 & 17 & 28 \\
\hline Fisher's exact test, $\mathrm{p}=0.174$ & & \\
\hline EGFR, epidermal growth factor receptor; PR, progesterone receptor \\
\hline
\end{tabular}

Table 2

b. Correlation of EGFR mutation and PR status of breast cancer

\begin{tabular}{|lllll|}
\hline No. & \multicolumn{2}{c}{ PR } & Total \\
\cline { 3 - 4 } & Negative & Positive & \\
\hline EGFR & Wild-type & 4 & 2 & 6 \\
\cline { 2 - 5 } & Mutated & 7 & 15 & 22 \\
\hline Total & 11 & 17 & 28 \\
\hline Fisher's exact test, $\mathrm{p}=0.174$ & & \\
\hline \multicolumn{2}{|l|}{ EGFR, epidermal growth factor receptor; PR, progesterone receptor } \\
\hline
\end{tabular}

We performed immunohistochemistry on 20 lung tumors. All patients were diagnosed as ER-negative, $95 \%(n=19)$ had wild-type ALK, and 85\% $(n=17)$ exhibited low Ki67 $(<30 \%)$. 


\section{Ct Imaging}

Of the 55 patients with primary breast cancer and lung cancer who underwent CT, pGGOs were reported in $54.5 \%(n=30)$, whereas mGGOs were found in $32.7 \%(n=18)$, sGGOs in $10.9 \%(n=6)$, and a combination of pGGO and sGGO in 1.8\% ( $n=1)$. The average tumor size among all patients was $14.2 \mathrm{~mm}$ (range, 4$29 \mathrm{~mm})$.

All patients with wild type EGFR $(n=6)$ exhibited pGGOs. Among patients with EGFR mutations, $7(31.8 \%)$ had pGGOs, 10 (45.5\%) had mGGOs, and $5(22.7 \%)$ had sGGOs (Table 3a; $p=0.012$ ).

Table 3

a. Correlation of EGFR and type of GGO

\begin{tabular}{|llllll|}
\hline & & \multicolumn{2}{c}{ NGO } & & \multicolumn{2}{c}{ Total } \\
\cline { 3 - 5 } & WGGO & mGGO & sGGO & \\
\hline \multirow{2}{*}{ EGFR } & Wild-type & 6 & 0 & 0 & 6 \\
\cline { 2 - 5 } & Mutated & 7 & 10 & 5 & 22 \\
Total & & 13 & 10 & 5 & 28 \\
\hline
\end{tabular}

Fisher's exact test, $\mathrm{p}=0.012$

EGFR, epidermal growth factor receptor; GGO, ground glass opacity; pGGO, pure GGO; mGGO, mixed GGO; sGGO, solid GGO

Table 3

b. Correlation of EGFR and change in CT imaging of first time to follow up

\begin{tabular}{|lllll|}
\hline No. & \multicolumn{2}{c}{ Change in CT } & Total \\
\cline { 2 - 4 } & & Stable lesion & Lesion progression & \\
\hline \multirow{2}{*}{ EGFR } & Wild-type & 6 & 0 & 6 \\
\cline { 2 - 5 } & Mutated & 13 & 9 & 22 \\
\hline Total & 19 & 9 & 28 \\
\hline Fisher's exact test, $\mathrm{p}=\mathbf{0 . 1 3 6}$ & & \\
\hline EGFR, epidermal growth factor receptor; CT, computed tomography
\end{tabular}

At the first follow-up CT, the majority of patients (63\% [ $=34]$ ) exhibited no changes in GGO size. GGO regression at the first follow-up was observed in 1 patient who underwent endocrine therapy. Thirteen patients (46.4\%) with EGFR mutation exhibited stable lesions at the first follow-up (Table 3a), but without statistical difference (Table $3 b ; p=0.136)$. 


\section{Sites And Intervals Of Double Primary Cancer}

Upon initial review of the 55 patients with double primary malignancy, 22 (40\%) exhibited tumors on the same side, 32 (58.2\%) had contralateral cancer (lung cancer occurring on the side opposite to the breast cancer), and 1 (1.8\%) exhibited bilateral breast cancer (Fig. 2). As shown in Table 4, the chi-square value was $3.422(P=0.064)$

Table 4

Site of spontaneous breast and lung cancer

lesions

\begin{tabular}{|lllll|}
\hline No. & \multicolumn{2}{c}{ Lung cancer } & Total \\
\cline { 2 - 4 } & & Left & Right & \\
\hline Breast cancer & Left & 9 & 20 & 29 \\
\cline { 2 - 5 } & Right & 14 & 11 & 29 \\
Total & 23 & 31 & 54 \\
\hline \multicolumn{2}{l}{ Chi-square 3.42 $\mathrm{p}=0.064$} & & \\
\hline
\end{tabular}

The interval from breast cancer surgery to diagnosis of lung cancer ranged from 0-420 months, with a mean of $35 \pm 13.0$ months. Notably, 50 patients were first diagnosed with breast cancer, 3 had breast cancer and lung cancer discovered at the same time, and only 2 developed lung cancer before breast cancer.

\section{Discussion}

Metastasis of breast cancer to the lungs is relatively common in clinical practice ${ }^{19}$. Therefore, in breast cancer patients who exhibit pulmonary nodules, lung metastasis is often the first diagnosis considered. However, a certain number of patients with breast cancer and primary lung cancer experience complications of solitary pulmonary nodules ${ }^{20}$. Therefore, it is necessary to understand the frequency of primary lung cancer in breast cancer patients.

To address the deficiency of information regarding the development of a second primary cancer following breast cancer, we retrospectively reviewed data from the Jiangsu Province Hospital to analyze all patients with breast cancer and second primary lung cancer, as well as those with breast cancer diagnosed as a second primary cancer after lung cancer, between 2008 and 2018. Our research provides further evidence demonstrating that the occurrence of lung cancer is closely related to the development of breast cancer, especially lung adenocarcinoma with EGFR mutation. As breast cancer patients live longer, there is an increased possibility of developing subsequent primary lung cancer owing to underlying genetic or other factors ${ }^{21}$. An interesting phenomenon in our study was the higher frequency of second lung cancer in patients with low-grade malignancies, which differed from our expectations. 
Breast cancer patients who were older, had ER-negative cancer, had a low Ki67 index, and displayed no lymph node metastasis exhibited a significantly higher rate of development of a second primary lung cancer. The characteristics of second lung cancer were strikingly similar: 100\% were ER-negative, 95\% had wild-type ALK, and 85\% exhibited low Ki67 (<30\%). Further, most patients had stable nodules at the first follow-up. We speculate that low malignancy contributes to longer survival times in cancer patients, and, given that the mean interval of diagnosis of double primary cancers was $35 \pm 13.0$ months, this was sufficient to permit the development of a second primary lung cancer.

Many previous studies have reported that second primary lung cancer rates are significantly higher in breast cancer patients than in patients with other primary cancers $8,16,21$, which is consistent with the results of our study. The incidence of secondary primary lung cancer in breast cancer patients may have previously been higher, as there was no pathological diagnosis in the remaining 345 patients with stable GGOs. Chest CT at regular intervals could result in increased detection of pulmonary nodules. Further, the occurrence of stable GGO may be related to common risk factors, including genetics, heredity, hormones, and environmental factors. Previous studies have reported that breast cancer patients who undergo radiotherapy ${ }^{15,22}$, smokers ${ }^{23}$, and those treated with chemotherapy ${ }^{11}$ have a higher possibility of developing secondary lung cancer.

Nevertheless, the higher risk for developing lung cancer in patients with primary breast cancer cannot be explained merely by regular follow-up. An interesting finding of our study was that the rate of EGFR mutation was as high as $75.6 \%$, which is almost twice that in patients with non-small cell lung cancer without another primary cancer ${ }^{24}$. This phenomenon has not been reported in previous studies. These observations suggest that EGFR signaling may play a crucial role in the development of concurrent lung and breast cancers. Several studies have reported that overexpression of EGFR is common in breast cancer patients and is associated with decreased survival ${ }^{25-28}$. Moreover, previous reports have indicated that ER signaling plays an important role in primary lung cancer following breast cancer, and that activation of ER signaling occurs through EGFR/HER-1, thus confirming a correlation between ER expression and EGFR mutation ${ }^{29-34}$. Patients with an acquired resistance to EGFR antagonists may, therefore, benefit from antiestrogen therapy ${ }^{12}$. Moreover, EGFR and HER2 are members of the human epidermal growth factor receptor family, which are type I transmembrane growth factor receptors that activate intracellular signaling pathways and are major determinants of human cancer ${ }^{35}$. According to previous studies, overexpression of EGFR is associated with apoptosis, angiogenesis, and formation of tumor vessels. Therefore, EGFR mutation may provide clues of a common etiological pathway between primary lung adenocarcinoma and breast cancer ${ }^{36,37}$.

Patients with a second primary lung cancer were less likely to have pGGOs and more likely to have sGGOs, and those with EGFR mutations exhibited a similar trend $(P=0.05)$. Analysis of the correlation between CT image patterns and gene mutations demonstrated no statistical significance. Similarly, most of the GGOs had not changed in size at the first follow-up. Unexpectedly, the lesion in one of the patients who underwent endocrine therapy shrunk, consistent with a previous report that breast cancer patients 
with second primary lung cancers who are treated with antiestrogen therapy exhibit longer cancer-specific survival ${ }^{12,33}$.

There were several limitations to the present study, the first of which was its retrospective, as opposed to prospective, design. Second, random variation and low statistical power resulted from the limited number of patients. Finally, the lack of long-term follow-up prevented us from observing more cancer-related events and assessing cancer-specific survival. The next step is to further follow up the patient, collect more clinical samples, and conduct basic research to explore its underlying mechanisms.

In conclusion, we observed that women diagnosed with breast cancer demonstrated an increased risk of second primary lung cancer. The present study is the first to report a higher rate of EGFR mutations in second primary lung cancer, which may play an important role in the development of double primary breast and lung cancer. This is an interesting clinical finding that can further the exploration of the mechanism behind elevated EGFR expression in patients with primary breast cancer and the mechanism of EGFR expression in lung cancer and breast cancer, paving the way for development of new drugs. Based on the results of the current research, we recommend that breast cancer patients who exhibit highrisk factors be closely followed. EGFR-targeted treatment represents an alternative option for these patients.

\section{Materials And Methods}

\section{Study population}

A review of medical charts at the Jiangsu Province Hospital (Jiangsu, China) revealed 8048 patients with pathologically confirmed breast cancer between January 2008 and December 2020. During this period, 6012 consecutive patients underwent diagnostic chest computed tomography (CT), and ground-glass opacities (GGOs) were detected in 890. Retrospective analysis of these patients' medical records revealed a total of 55 patients with histologically confirmed lung adenocarcinoma. Clinical information, including pathology and immunohistochemistry of cancer tissues, EGFR status, date of GGO detection, and cancer stage, was collected. All the CT images were evaluated by two senior radiologists retrospectively.

\section{Follow-up}

All patients were evaluated at 3- or 4-month intervals by chest CT. CT findings, including lesion size and radiological features, were confirmed by at least two radiologists. Imaging characteristics were visually classified into four subgroups: pure GGO (pGGO), mixed GGO (mGGO), solid GGO (sGGO), and combined GGO.

\section{Ethical parameters statement}

The study was approved by the Institutional Review Board of the First Affiliated Hospital of Nanjing Medical University (approval number 2018-SR-273). Clinical data were collected from patients after 
obtaining informed consent. All experiments were performed in accordance with the Declaration of Helsinki.

\section{Statistical analysis}

Statistical analysis was performed using SPSS version 21.0 (IBM Corporation, Armonk, NY, USA). Measurement data are expressed as mean \pm standard deviation, and the t-test was used for comparison between groups. The chi-squared test was used for categorical variables, and Fisher's exact test was used for data in which more than $20 \%$ of cells had expected frequencies $<5$. The correlation of breast cancer factors with primary lung cancer was analyzed using logistic regression analysis. The standardized incidence ratio (SIR) of lung cancer in patients with breast cancer was then calculated by dividing the number of observed cases by the number of expected cases in the general Chinese population. P-values < 0.05 were considered to be statistically significant.

\section{Declarations}

\section{DATA AVAILABILITY STATEMENT}

The data analysed during the research are included in this study or are available on reasonable request.

\section{AUTHOR CONTRIBUTIONS}

T Z: Conceptualization, data curation, formal analysis, software, writing-original draft, and writing-review and editing. HX: Conceptualization, data curation, formal analysis, writing-original draft, and writingreview and editing. Y L: Conceptualization, data curation, formal analysis, writing-original draft, and writing-review and editing. Y Y: Data curation, formal analysis, and writing-review and editing. F Y: Data curation, formal analysis, and writing-review and editing. M Y: Data curation, and writing-review and editing. Chunxiao Sun: Data curation and writing-review and editing. $S \mathbf{B}, \mathbf{X Y}, \mathbf{Y} \mathrm{H}, \mathrm{Y} H, X \mathrm{X}, \mathrm{M}$ J: Formal analysis, and writing-review and editing. $\mathbf{X ~ H}$ : Formal analysis and writing-review and editing. $\mathbf{J} \mathbf{L}, \mathbf{Y} \mathbf{L}$ : Formal analysis and writing-review and editing. Z F: Formal analysis and writing-review and editing. W L: Conceptualization, formal analysis, and writing-review and editing. Y Y: Conceptualization, formal analysis, funding acquisition and writing-review and editing.

\section{FUNDING}

This study was financially supported by the National Key Research and Development Program of China (ZDZX2017ZL-01), High-level innovation team of Nanjing Medical University (JX102GSP201727), Wu Jieping Foundation (320.6750.17006), Key Medical Talents (ZDRCA2016023), 333 Project of Jiangsu Province (BRA2017534 and BRA2015470), the collaborative innovation center for tumor individualization focuses on open topics (JX21817902/008), and Project of China key research and development program precision medicine research (2016YFC0905901).

\section{ACKNOWLEDGMENTS}


The authors would like to thank Lei Wang for excellent technical support and Professor Xichun Hu for critically reviewing the manuscript.

\section{References}

1. Sung, H. et al. Global Cancer Statistics 2020: GLOBOCAN Estimates of Incidence and Mortality Worldwide for 36 Cancers in 185 Countries. CA Cancer J Clin, 71, 209-249 https://doi.org/10.3322/caac.21660 (2021).

2. Hayat, M. J., Howlader, N., Reichman, M. E. \& Edwards, B. K. Cancer statistics, trends, and multiple primary cancer analyses from the Surveillance, Epidemiology, and End Results (SEER) Program. Oncologist, 12, 20-37 https://doi.org/10.1634/theoncologist.12-1-20 (2007).

3. Mariotto, A. B., Rowland, J. H., Ries, L. A., Scoppa, S. \& Feuer, E. J. Multiple cancer prevalence: a growing challenge in long-term survivorship. Cancer Epidemiol Biomarkers Prev, 16, 566-571 https://doi.org/10.1158/1055-9965.EPI-06-0782 (2007).

4. Utada, M., Ohno, Y., Hori, M. \& Soda, M. Incidence of multiple primary cancers and interval between first and second primary cancers. Cancer Sci, 105, 890-896 https://doi.org/10.1111/cas.12433 (2014).

5. Molina-Montes, E. et al. Risk of second cancers cancer after a first primary breast cancer: a systematic review and meta-analysis. Gynecol Oncol, 136, 158-171 https://doi.org/10.1016/j.ygyno.2014.10.029 (2015).

6. Molina-Montes, E. et al. Risk of second primary cancer among women with breast cancer: a population-based study in Granada (Spain). Gynecol Oncol, 130, 340-345 https://doi.org/10.1016/j.ygyno.2013.04.057 (2013).

7. Miller, K. D. et al. Cancer treatment and survivorship statistics, 2019. CA Cancer J Clin, 69, 363-385 https://doi.org/10.3322/caac.21565 (2019).

8. Lee, K. D. et al. Increased risk for second primary malignancies in women with breast cancer diagnosed at young age: a population-based study in Taiwan. Cancer Epidemiol Biomarkers Prev, 17, 2647-2655 https://doi.org/10.1158/1055-9965.EPI-08-0109 (2008).

9. Oya, H., Murayama, E. \& Okino, M. [Primary lung cancer found following mastectomy for breast cancer]. Kyobu Geka, 21, 510-514 (1968).

10. Salomon, R., Lopez-Velez, R., Pasquau, F., Lafuente, J. \& Gallar, P. [Lung cancer as a second primary cancer in patients with breast cancer. Presentation of 4 cases]. Rev Clin Esp, 169, 51-54 (1983).

11. He, K. W. et al. [Clinicopathological features of second primary lung cancer and pulmonary metastasisin patients with breast cancer]. Zhonghua Zhong Liu Za Zhi, 40, 201-205 https://doi.org/10.3760/cma.j.issn.0253-3766.2018.03.008 (2018).

12. Hsu, L. H. et al. Second primary lung cancers among breast cancer patients treated with antiestrogens have a longer cancer-specific survival. Anticancer Res, 35, 1121-1127 (2015). 
13. Kerendi, F., Gal, A., Corvera, J. S., Halkos, M. E. \& Miller, J. I. Characteristics of second primary lung malignancy in patients with known breast cancer. South Med J, 102, 269-274 https://doi.org/10.1097/SMJ.0b013e318197fec6 (2009).

14. Schonfeld, S. J., Curtis, R. E., Anderson, W. F. \& de Berrington, A. The risk of a second primary lung cancer after a first invasive breast cancer according to estrogen receptor status. Cancer Causes Control, 23, 1721-1728 https://doi.org/10.1007/s10552-012-0054-3 (2012).

15. Grantzau, T., Thomsen, M. S., Vaeth, M. \& Overgaard, J. Risk of second primary lung cancer in women after radiotherapy for breast cancer. Radiother Oncol, 111, 366-373 https://doi.org/10.1016/j.radonc.2014.05.004 (2014).

16. Watanabe, S. et al. Frequency of multiple primary cancers and risk factors for lung and breast cancer patients. Princess Takamatsu Symp, 18, 275-282 (1987).

17. Huang, Y. J. et al. Radiation Therapy for Invasive Breast Cancer Increases the Risk of Second Primary Lung Cancer: A Nationwide Population-Based Cohort Analysis. J Thorac Oncol, 12, 782-790 https://doi.org/10.1016/j.jtho.2017.01.021 (2017).

18. Chen, W. et al. Cancer statistics in China, 2015. CA Cancer J Clin, 66, 115-132 https://doi.org/10.3322/caac.21338 (2016).

19. Tarutinov, V. I., Bukavin, A. S. \& Skliar, S. [Prognostic criteria of breast cancer metastasis to the lungs].Klin Khir,10-12(1995).

20. Xu, H. et al. Incidence and natural course of CT-detected pulmonary ground-glass nodules in Chinese women with breast cancer: a retrospective, single-center, long-term follow-up study in 4682 consecutive patients. Acta Radiol, 61, 175-183 https://doi.org/10.1177/0284185119856259 (2020).

21. Wang, R. et al. Second Primary Lung Cancer After Breast Cancer: A Population-Based Study of 6,269 Women. Front Oncol, 8, 427 https://doi.org/10.3389/fonc.2018.00427 (2018).

22. Struikmans, H. et al. [Trends in the use of primary radiotherapy for cancer in the Netherlands in patients with breast, prostate, rectal and lung tumours]. Ned Tijdschr Geneeskd, 156, A4426 (2012).

23. Kaufman, E. L., Jacobson, J. S., Hershman, D. L., Desai, M. \& Neugut, A. I. Effect of breast cancer radiotherapy and cigarette smoking on risk of second primary lung cancer. J Clin Oncol, 26, 392-398 https://doi.org/10.1200/JC0.2007.13.3033 (2008).

24. Wei, B. et al. Quantification of EGFR mutations in primary and metastatic tumors in non-small cell lung cancer. J Exp Clin Cancer Res, 33, 5 https://doi.org/10.1186/1756-9966-33-5 (2014).

25. Levva, S. et al. Prognostic Evaluation of Epidermal Growth Factor Receptor (EGFR) Genotype and Phenotype Parameters in Triple-negative Breast Cancers. Cancer Genomics Proteomics, 14, 181-195 https://doi.org/10.21873/cgp.20030 (2017).

26. Siziopikou, K. P. \& Cobleigh, M. The basal subtype of breast carcinomas may represent the group of breast tumors that could benefit from EGFR-targeted therapies., 16, 104-107 https://doi.org/10.1016/j.breast.2006.09.003 (2007).

27. Burness, M. L., Grushko, T. A. \& Olopade, O. I. Epidermal growth factor receptor in triple-negative and basal-like breast cancer: promising clinical target or only a marker? Cancer J, 16, 23-32 
https://doi.org/10.1097/PPO.0b013e3181d24fc1 (2010).

28. Alanazi, I. O. \& Khan, Z. Understanding EGFR Signaling in Breast Cancer and Breast Cancer Stem Cells: Overexpression and Therapeutic Implications. Asian Pac J Cancer Prev, 17, 445-453 https://doi.org/10.7314/apjcp.2016.17.2.445 (2016).

29. Siegfried, J. M. \& Stabile, L. P. Estrongenic steroid hormones in lung cancer. Semin Oncol, 41, 5-16 https://doi.org/10.1053/j.seminoncol.2013.12.009 (2014).

30. Stabile, L. P. et al. Combined targeting of the estrogen receptor and the epidermal growth factor receptor in non-small cell lung cancer shows enhanced antiproliferative effects. Cancer Res, 65, 1459-1470 https://doi.org/10.1158/0008-5472.CAN-04-1872 (2005).

31. Stabile, L. P. et al. Prevention of tobacco carcinogen-induced lung cancer in female mice using antiestrogens., 33, 2181-2189 https://doi.org/10.1093/carcin/bgs260 (2012).

32. Nose, N. et al. Association between estrogen receptor-beta expression and epidermal growth factor receptor mutation in the postoperative prognosis of adenocarcinoma of the lung. J Clin Oncol, 27, 411-417 https://doi.org/10.1200/JC0.2008.18.3251 (2009).

33. Garon, E. B. et al. Antiestrogen fulvestrant enhances the antiproliferative effects of epidermal growth factor receptor inhibitors in human non-small-cell lung cancer. J Thorac Oncol, 8, 270-278 https://doi.org/10.1097/JT0.0b013e31827d525c (2013).

34. Mazieres, J. et al. Specificities of lung adenocarcinoma in women who have never smoked. $J$ Thorac Oncol, 8, 923-929 https://doi.org/10.1097/JTO.0b013e3182904dfb (2013).

35. Yarden, Y. \& Sliwkowski, M. X. Untangling the ErbB signalling network. Nat Rev Mol Cell Biol, 2, 127137 https://doi.org/10.1038/35052073 (2001).

36. Althuis, M. D. et al. Etiology of hormone receptor-defined breast cancer: a systematic review of the literature. Cancer Epidemiol Biomarkers Prev, 13, 1558-1568 (2004).

37. Yeh, J. et al. Clinical Characteristics in Patients with Triple Negative Breast Cancer. Int J Breast Cancer 2017, 1796145, doi:10.1155/2017/1796145 (2017).

\section{Figures}




\section{EGFR and ER}

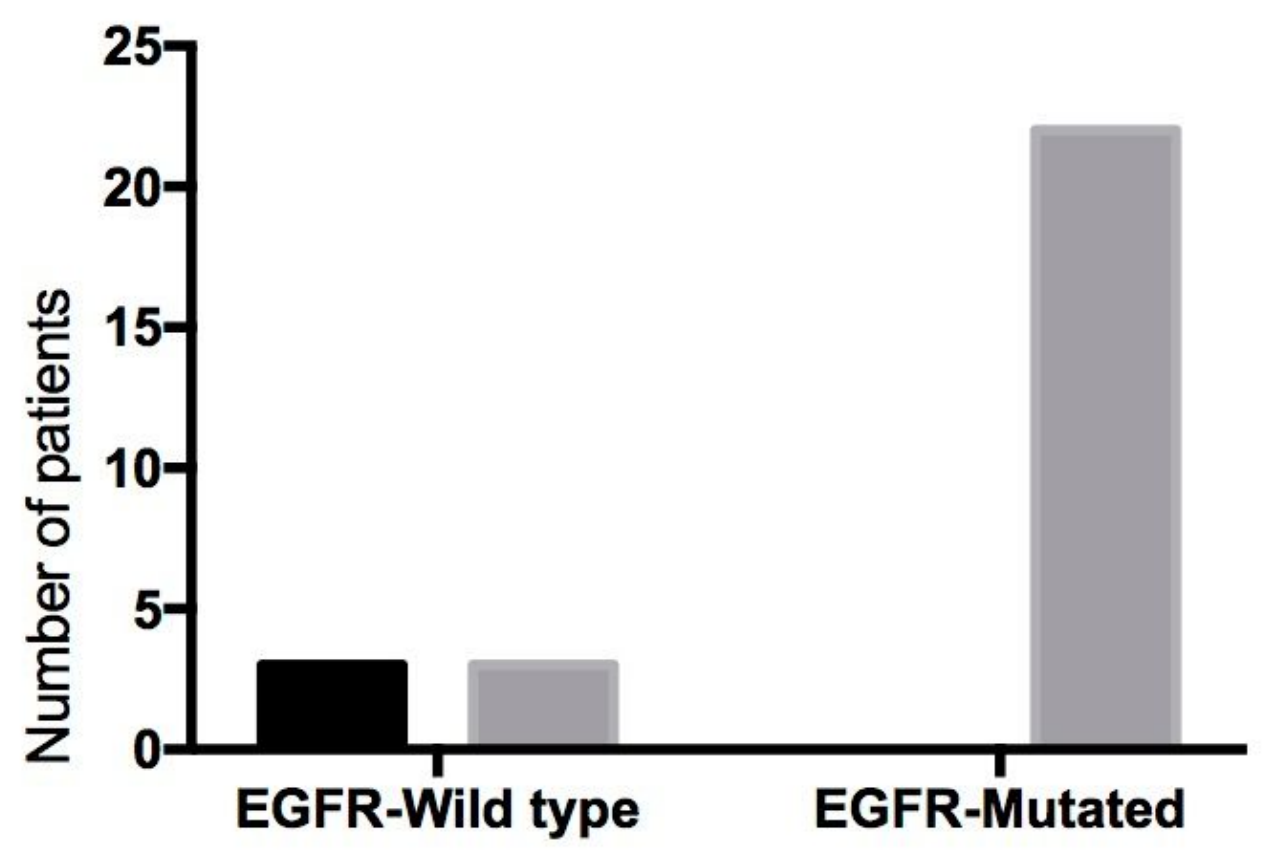

\section{ER-NEGATIVE ER-POSITIVE}

Figure 1

Relevance of status of EGFR and ER 


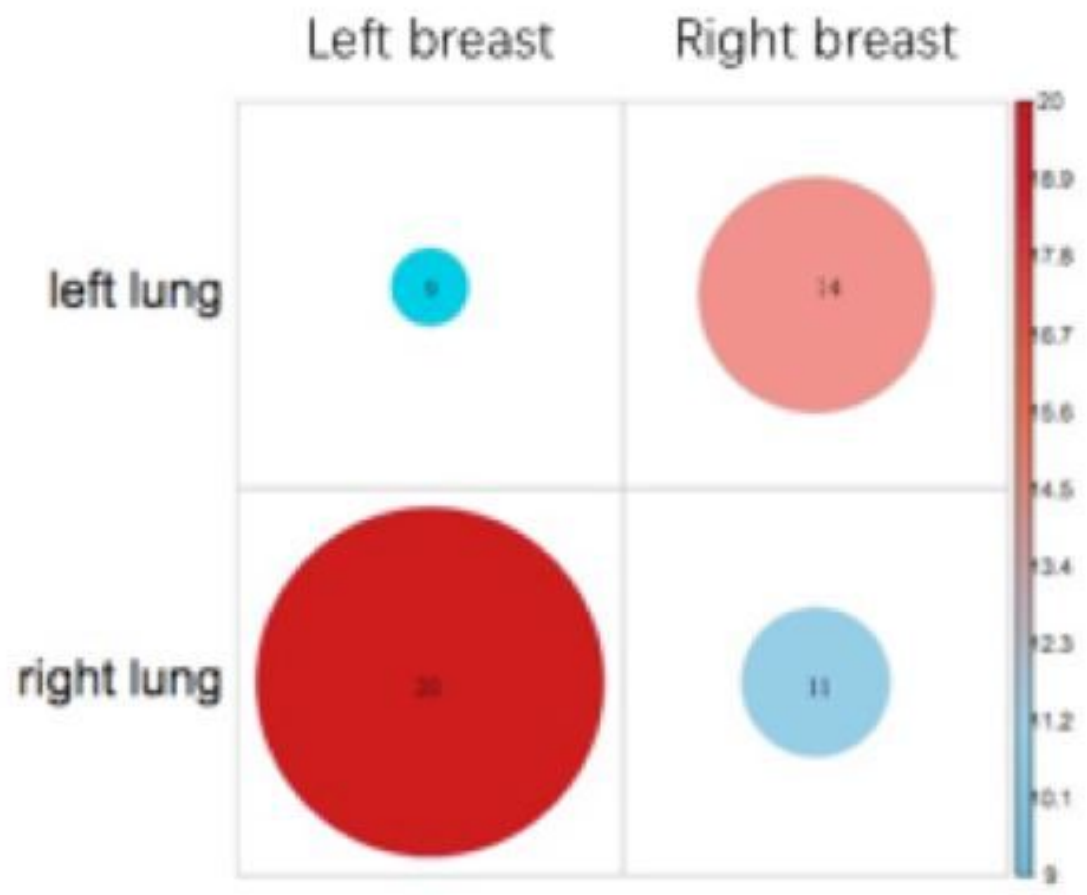

Figure 2

Site of spontaneous breast and lung cancer lesions 